J Neurosurg Pediatrics 13:706, 2014

(C)AANS, 2014

\title{
Erratum
}

\section{Neuroendoscopic lavage for the treatment of intraventricular hemorrhage and hydrocephalus in neonates}

\section{Clinical article}

To The ReAdership: An error was introduced during preparation of the article "Neuroendoscopic lavage for the treatment of intraventricular hemorrhage and hydrocephalus in neonates. Clinical article" (JNeurosurg Pediatr, published online ahead of print on April 4, 2014; DOI: 10.3171/ 2014.2.PEDS13397).

After online publication of the article, we realized that there was an error in the last sentence of the Results section of the Abstract. The incorrect sentence was:

Endoscopic lavage was not associated with significantly fewer numbers of overall necessary procedures (median $2 \mathrm{vs}$ 3.5 per patient, respectively; $\mathrm{p}=0.08$ ), significantly fewer infections ( 2 vs 5 patients, respectively; $p<0.05$ ), or supratentorial multiloculated hydrocephalus ( 0 vs 4 patients, respectively; $\mathrm{p}<0.01$ )
Please include this information when citing this paper: published online May 2, 2014; DOI: 10.3171/2014.4.PEDS13397a.
This sentence has been corrected to the following:

Endoscopic lavage was associated with fewer numbers of overall necessary procedures (median 2 vs 3.5 per patient, respectively; $p=0.08$ ), significantly fewer infections ( 2 vs 5 patients, respectively; $\mathrm{p}<0.05$ ), and supratentorial multiloculated hydrocephalus ( 0 vs 4 patients, respectively; $p<0.01$ ).

We apologize to the authors and readers. We corrected the text in the Abstract online as of May 2, 2014, and the correct version is printed in this issue.

Gillian Shasby Director of Publications-Operations Journal of Neurosurgery Publishing Group Charlottesville, VA 